\title{
POSTOPERATIVE ANTIBACTERIAL PROPHYLAXIS IN VASCULAR SURGERY: ANALYSIS OF ITS PARAMETERS BEFORE AND AFTER EVALUATION OF JUSTIFICATION OF CHOSEN INDICATIONS
}

\author{
Edgars Supols \\ Riga Stradins University
}

\begin{abstract}
Summary
In surgical practice, antibacterial prophylaxis (AP) is widely used to reduce the risk of possible infectious complications; it is not always administrated according to evidence-based clinical indications. Administration of AP in cases when its inefficiency for exact situation has been scientifically proven, should be considered as unwarranted. A one-year-long retrospective analysis of AP cases in the Department of Vascular Surgery of Pauls Stradins Clinical University Hospital was performed and the results were broadly analyzed within the local structural unit. It was followed by the development of the local guidelines for administration of antibiotics, as a result, a significant decrease in cases of unwarranted AP has been achieved.
\end{abstract}

Keywords: antibacterial prophylaxis, vascular surgery

\section{INTRODUCTION}

Infectious complications are one of the most frequent complications of surgical therapy, which complicates and prolongs the treatment process, increases its costs, and are accompanied with high mortality rate $(2,16)$. Surgical site infection (SSI) is the most common one, with different incidence rates in different surgical specialties. In vascular surgery, it varies by the type of surgical intervention, overall up to $27 \%$. $(15,9)$ The specification of vascular surgery requires frequent use of synthetic materials (vascular prostheses and patches), which, in case of infection, is associated with higher threats. Vascular graft infection (VGI) occurs in $0,5 \%$ to $6 \%$, but is particularly significant due to frequent lower limb amputations (up to 70\%) and high mortality rate $(15-75 \%)$. $(10,13)$

On the one hand, several clinical risk factors have been related to these infections such as diabetes mellitus $(3,5,8,12,15,18,19)$, tissue ischaemia due to vasculopathy $(5,13,15,17,19)$, obesity $(8,10,15$, $17,19)$, reoperation due to surgical site hematoma $(6,7,8,11)$. There are several possible pathogenetic mechanisms for an early VGI, but the main risk factor is SSI. (8) Therefore it can be considered that the risk factors for the vascular graft infections are the same as for SSI.

On the other hand, antibiotic prophylaxis (AP) is being applied frequently for the purpose of reducing the risk of infectious complications. Nevertheless studies do not demonstrate the achievement of expected benefits in all cases. Reduced risk of infectious complications has been approved for administration of AP preoperatively. However, AP prolongation for more than 24 hours after a surgery does not have the same reducing effect, but increases the risk of the side effects of antibiotics. $(8,4,14,1,15)$ It should be noted that there is a lack of studies analysing effects of postoperative antibiotic prophylaxis (PAP) for patients with predisposing factors to infection, mentioned before. In these cases the decision about PAP - to administer it or not, the duration and other characteristics of PAP-is made based on a physician's individual consideration. However, in cases when a patient has no risk factors for increased infectious complications, PAP should be considered as unwarranted. Moreover, the unreasonable use of antibacterial agents should be eliminated in the context of antimicrobial resistance problem.

\section{THE STUDY DESCRIPTION}

A retrospective analysis of the surgical procedures was performed in the Department of Vascular Surgery (DVS) of Pauls Stradins Clinical University Hospital (PSCUH) from $1^{\text {st }}$ January, 2018 to $31^{\text {st }}$ December, 2018 (a calendar year) using the following criteria:

- $\quad$ primary diagnosis the surgery was performed for;

- information about the surgical intervention;

- information about the patient-related risk factors for higher infection risk;

- duration of received AP.

The data as statistical summary was presented and analysed during the PSCUH DVS session on $8^{\text {th }}$ March, 2019. In cooperation with the Infection Surveilance Service the guidelines for the use of antibacterial agents have been developed. In order to analyse, whether the evaluation of systematic habits of individual physicians and the development of local guidelines have changed the previous habitual practice of administration of unwarranted PAP, the data of performed surgeries in 
PSCUH DVS from $11^{\text {th }}$ March, 2019 to $11^{\text {th }}$ July, 2019 (a trimester of a calendar year following the session) were collected and analysed.

At the same time the data about SSI and VGI cases from $1^{\text {st }}$ January, 2018 to $11^{\text {th }}$ July 2019 were collected. An excluding criteria for both, SSI and VGI, was a surgery performed on an active infection already existing, and for VGI cases - graft implantation performed before the time period of the review.

\section{RESULTS}

The total number of PAP cases (both with and without risk factors for increased infectious complications) registered in 2018 was 671 , with a proportion to total surgical intervention cases of $56,10 \%$. The data about the patients who received the surgery and were administered unwarranted PAP from $1^{\text {st }}$ January to $31^{\text {st }}$ December, 2018 are shown in Table 1.

Dividing general groups more precisely, unwarranted PAP is most frequent after the endarterectomies of the abdominal aorta, iliac and femoral arteries (in 96 of 242 interventions or in 39,67 \%), thrombembolectomies from the arteries of the lower limb (in 10 of 41 interventions or in $24,39 \%$ ), bypass surgery of the popliteal and crural arteries (in 15 of 107 interventions or in $14,02 \%$ ) bypass surgery of abdominal aorta, iliac and femoral arteries (in 22 of 204 interventions or in $10,78 \%$ ). Based on these results, the conclusion is made, that in clinical practice surgical intervention on the arteries of the lower limb by physicians is considered as the indication for PAP, nevertheless it is not an evidence-based argument. Of the total 399 performed endarterectomies of the carotid artery in 15 cases $(3,67 \%)$ PAP was administered with an average duration 2,53 days, although the risk for infectious complications after the surgery on carotid artery statistically is one of the lowest ones.

In $59,17 \%$ duration of PAP was longer than one day (an average 2,75 days). The amplitude of the average duration of PAT analysed by each physician separately was calculated from 1,22 to 4,29 days.

The data about the patients who received the surgery and were administered unwarranted PAP from $11^{\text {th }}$ May to $11^{\text {th }}$ July 2019 are shown in Table 2 .

To realise if the habitual practice of administration of unwarranted PAP has changed, the data about both periods were compared and illustrated in Figure 1.

The number of unwarranted PAP cases has been completely reduced both in the group of reconstructions of the carotid and subclavian artery and extraanatomical bypass surgery. Also a decrease was observed in the following groups: reconstructions of the abdominal aorta, iliac and femoral arteries (- 10,70\%), extra-anatomical bypass surgery $(-9,68 \%)$, others $(-8,66 \%)$.

An increase was observed in the following groups: reconstructions of the popliteal and crural arteries $(+3,63 \%)$, endovascular surgery $(+2,05 \%)$. Due to the low number of interventions in some groups (Table 2.), the calculated percentage may not accurately reflect the true situation in the longer period of time. To avoid such a statistical error, data registration should be continued. The highest frequency of unwarranted PAP still remains to endarterectomies of the abdominal aorta, iliac and femoral arteries $(20,00 \%)$ and bypass surgery on popliteal and crural arteries (17,65\%). Reduction of the total frequency of unwarranted PAP has been calculated as 6,97 \%.

Out of 33 cases of unwarranted PAP (an average duration 2,27 days), in $15(45,46 \%)$ the treatment has been administered for more than one day, and 14 cases of them have been reported to the same physician with an average duration of 3,57 days.

The total number of PAP cases (both, with and without risk factors for increased infectious complications) registered in the trimester of 2019 is 138, with a proportion to total surgical intervention cases of $29,94 \%$ (a decrease of $25,5 \%$ ).

As to these changes, at the same time no negative impact has been identified on the frequency of SSI ( 9 cases in 2018, 2 cases in the trimester of 2019) or VGI ( 5 cases in 2018, 1 case in the trimester of 2019).

\section{CONCLUSIONS}

1. The efficiency of postoperative antibacterial prophylaxis has not been established. Nevertheless, it is widely administered to patients with no risk factors for increased infectious complications, exposing them to the risk for developing antibiotic agent caused side effects and promoting the evolution of antibiotic resistance.

2. There is a lack of precise guidelines of the necessity of postoperative antibiotic prophylaxis for patients with clinically increased risks for infectious complications (but no infection).

3. The analysis of cases of antibacterial prophylaxis is recommended within the hospital_or its structural unit to decrease the frequency of unwarranted administration of antibacterial agents.

4. It is recommended to analyse other parameters of antibacterial prophylaxis - antibacterial agents that are used in therapy, their combinations, the frequency of complications etc.

Conflict of interest: None 
Table 1. Frequency of unwarranted AP casas different groups of performed surgery in 2018.

\begin{tabular}{l}
\cline { 2 - 5 } \multicolumn{1}{c|}{} \\
\cline { 2 - 5 }
\end{tabular}

Table 2. Frequency of unwarranted AP casas different groups of performed surgery inthe trimester of 2019.

\begin{tabular}{|c|c|c|c|}
\hline & 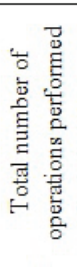 & 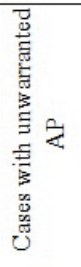 & 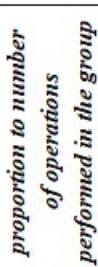 \\
\hline & abs. & abs. & $\%$ \\
\hline Reconstructions of the carotid and subclavian arteries & 187 & 0 & 0,00 \\
\hline Reconstructions of the abdominal aorta, iliac and femoral arteries & 170 & 23 & 13,53 \\
\hline Reconstructions of the popliteal and crural arteries & 34 & 6 & 17,65 \\
\hline Extra-anatomical bypass surgery & 13 & 0 & 0,00 \\
\hline Thrombembolectomies & 14 & 1 & 7,14 \\
\hline Endovascular surgery & 22 & 1 & 4,55 \\
\hline Others & 21 & 2 & 9,52 \\
\hline Total & 461 & 33 & 7,16 \\
\hline
\end{tabular}

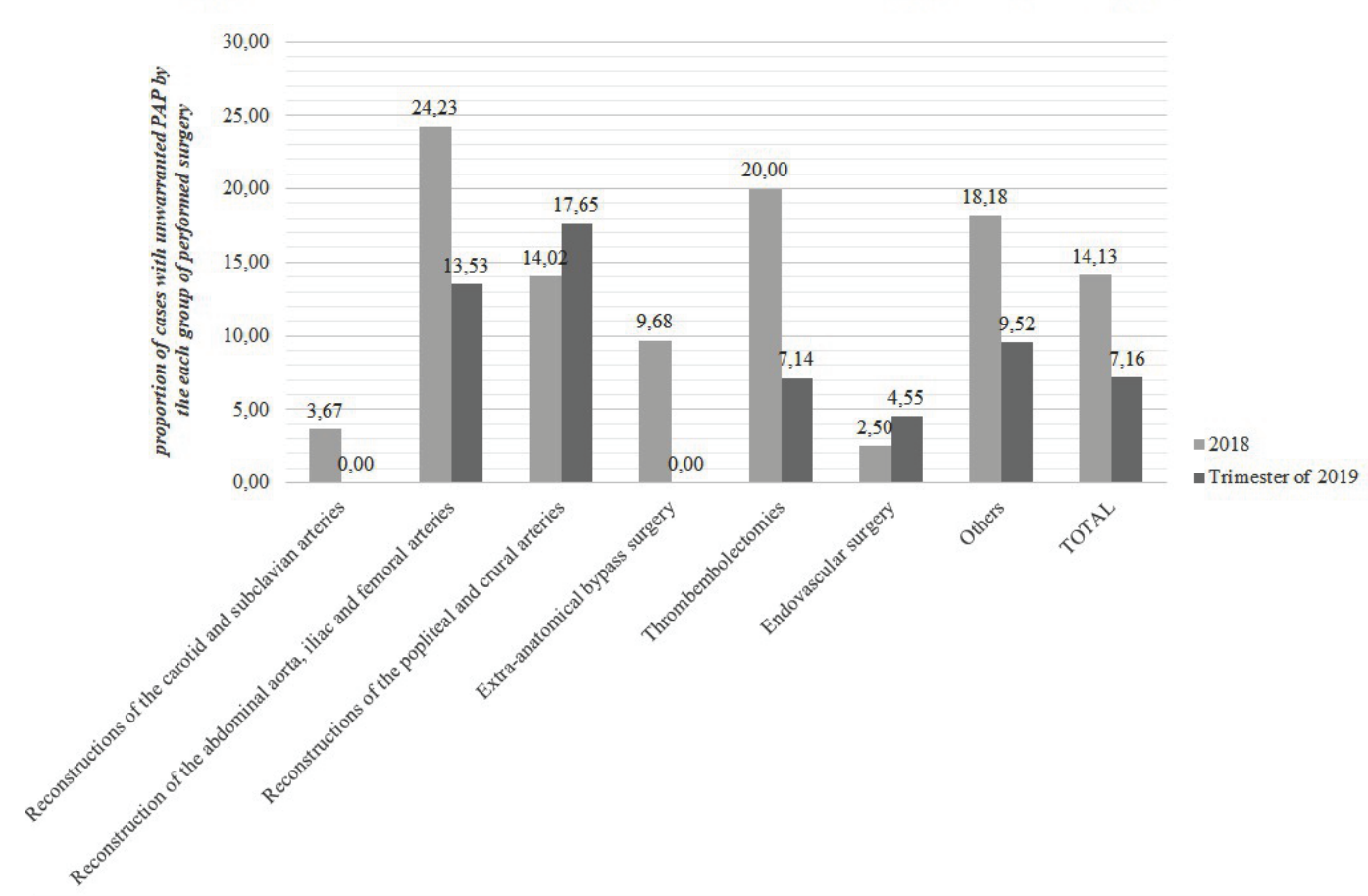

Fig. 1. Changes in the proportion of cases with unwarranted PAP by the each group of prformed surgery 


\section{REFERENCES}

1. Asundi A, Stanislawski M, Mehta P, Barón AE, Gold H, Mull H, Ho PM, Gupta K, Branch-Elliman W. Prolonged antimicrobial prophylaxis following cardiac device procedures increases preventable harm: insights from the VA CART program // Infect Control Hosp Epidemiol, 2018; 39(9):1030-1036.

2. Badia JM, Casey AL, Petrosillo N, Hudson PM, Mitchell SA, Crosby C. Impact of surgical site infection on healthcare costs and patient outcomes: a systematic review in six European countries // J Hosp Infect, 2017; 96(1):1-15

3. Boyle AJ, Rizer JM, Hodgkiss-Harlow KD, Armstrong PA, Bandyk DF. Surgical Site Infection after Arterial Intervention with a Groin Incision // J Vasc Surg, 2010; 52(6):1734-1735.

4. Branch-Elliman W, O'Brien W, Strymish J, Itani K, Wyatt C, Gupta K. Association of Duration and Type of Surgical Prophylaxis With AntimicrobialAssociated Adverse Events // JAMA Surg, 2019; 154(7):590-598.

5. Cheadle WG. Risk factors for surgical site infection // Surg Infect (Larchmt), 2006; 7 Suppl 1:S7-1 1.

6. Fagotti L, Ejnisman L, Gurgel H, Miyahara H, Croci A, Vicente J. Two Classifications for Surgical Wound Hematoma After Total Hip Replacement // Acta Ortop Bras, 2018; 26(1):11-15.

7. Figuerola-Tejerina A, Rodríguez-Caravaca G, Bustamante-Munguira J, María San RománMontero J, Durán-Poveda M. Epidemiological Surveillance of Surgical Site Infection and its Risk Factors in Cardiac Surgery: A Prospective Cohort Study // Rev Esp Cardiol (Engl Ed), 2016; 69(9):842-8.

8. Homer-Vanniasinkam S. Surgical site and vascular infections: treatment and prophylaxis // Int J Infect Dis, 2007; 11 Suppl 1:S17-22.

9. Inui T, Bandyk DF. Vascular surgical site infection: risk factors and preventive measures // Semin Vasc Surg, 2015; 28(3-4):201-7.

10. Kilic A, Arnaoutakis DJ, Reifsnyder T, Black JH 3rd, Abularrage CJ, Perler BA, Lum YW. Management of infected vascular grafts // Vasc Med, 2016; $21(1): 53-60$.

11. Kuy S, Dua A, Desai S, Dua A, Patel B, Tondravi N, Seabrook GR, Brown KR, Lewis BD, Lee CJ, Kuy $\mathrm{S}$, Subbarayan R, Rossi PJ. Surgical site infections after lower extremity revascularization procedures involving groin incisions // Ann Vasc Surg, 2014; 28(1):53-8.
12. Martin ET, Kaye KS, Knott C, Nguyen H, Santarossa M, Evans R, Bertran E, Jaber L. Diabetes and Risk of Surgical Site Infection: A systematic review and meta-analysis // Infect Control Hosp Epidemiol, 2016; 37(1):88-99.

13. Sousa JV, Antunes L, Mendes C, Marinho A, Gonçalves A, Gonçalves O, Matos A. Prosthetic vascular graft infections: A center experience // Angiol Cir Vasc, 2014; 10(2):52-57

14. Suehiro T, Hirashita T, Araki S, Matsumata T, Tsutsumi S, Mochiki E, Kato H, Asao T, Kuwano H. Prolonged antibiotic prophylaxis longer than 24 hours does not decrease surgical site infection after elective gastric and colorectal surgery // Hepatogastroenterology, 2008; 55(86-87):1636-9.

15. Turtiainen J, Saimanen E, Partio T, Kärkkäinen J, Kiviniemi V, Mäkinen K, Hakala T. Surgical wound infections after vascular surgery: prospective multicenter observational study // Scand J Surg, 2010; 99(3):167-72.

16. Urban JA. Cost analysis of surgical site infections // Surg Infect (Larchmt), 2006; 7 Suppl 1:S19-22

17. van Walraven C, Musselman R. The Surgical Site Infection Risk Score (SSIRS): A Model to Predict the Risk of Surgical Site Infections // PLoS One, 2013; 8(6):e67167.

18. Wilson WR, Bower TC, Creager MA, Amin-Hanjani S, O'Gara PT, Lockhart PB, Darouiche RO, Ramlawi B, Derdeyn CP, Bolger AF, Levison ME, Taubert KA, Baltimore RS, Baddour LM. Vascular Graft Infections, Mycotic Aneurysms, and Endovascular Infections: A Scientific Statement From the American Heart Association // Circulation, 2016; 134(20):e412-e460.

19. Wiseman JT, Fernandes-Taylor S, Barnes ML, Saunders RS, Saha S, Havlena J, Rathouz PJ, Kent KC. Predictors of surgical site infection after hospital discharge in patients undergoing major vascular surgery // J Vasc Surg, 2015; 62(4):10231031.e5.

\section{Address}

Edgars Supols

Riga Stradins University

Dzirciema street 16, Riga, LV-1007

E-mail: edgars.supols@rsu.edu.lv 